\title{
Description of Posner Schlossman Syndrome Patients in Bandung, Indonesia during the Period of August 2009 to July 2011
}

\author{
Kavitha Arunasalam ${ }^{1}$, Erna Tjahjaningtyas ${ }^{2}$, RA.Retno Ekowati ${ }^{3}$ \\ ${ }^{1}$ Faculty of Medicine, Universitas Padjadjaran, Bandung, Indonesia, ${ }^{2}$ Department of \\ Ophthalmology, Faculty of Medicine, Universitas Padjadjaran/National Eye Center Cicendo \\ Hospital, Bandung, Indonesia, ${ }^{3}$ Department of Cell Biology, Faculty of Medicine, Universitas \\ Padjadjaran, Bandung, Indonesia
}

\begin{abstract}
Background: Posner-Schlossman Syndrome (PSS) is also known as Glaucomatocyclitic Crisis. It is a nongenetic, often misdiagnosed, and rare disease characterized by recurrent unilateral episodes of markedly elevated intraocular pressure which occurs simultaneously with mild inflammation of the uvea. The underlying cause of this disease is still unknown. This syndrome usually affects those who are 20 to 50 years old. The aim of this study was to perform a descriptive study on subjects diagnosed with PSS at the National Eye Centre Cicendo Eye Hospital Bandung Indonesia.

Methods: The method used was a descriptive study carried out on subjects diagnosed with PSS at the National Eye Centre Cicendo Eye Hospital Bandung, Indonesia during the period of August 2009 to July 2011.

Results: Of 31 patients, 19 (61.3\%) female patients participated in the study, 12 (38.7\%) aged 31-40 years, $9(29.0 \%)$ had recurrences. All (100\%) complained of blurred vision, 24 (77.4\%) with accompanying vision of rainbow halo surrounding light in, and $22(71 \%)$ had headache. A total of $27(87.1 \%)$ patients suffered from the disease unilaterally. After treatment, 17 (54.8\%) patients' visual acuity improved and 20 (64.4\%) patients' intraocular pressure (IOP) were in normal range.

Conclusions: PSS mostly affects females. The most prevalent age range is 31-40 years. Most are affected unilaterally. All of them present with the symptom of blurred vision. Visual acuity and IOP are in normal limit after treatment.
\end{abstract}

Keywords: Eye vision, Posner Schlossman Syndrome, National Eye Centre Cicendo Eye Hospital

\section{Introduction}

Eyes are one of the important organs in our body. It is said to be the most complex and vital ones as they are crucial for our vision. ${ }^{1}$ Two hundred and eighty five million people are visually impaired worldwide and out of these, 38 millionto 39 million are blind and 246 million have low vision. About $90 \%$ of the them live in developing countries. Eighty percent of all visual impairment can be prevented or cured. ${ }^{2,3}$

Posner Schlossman Syndrome (PSS), also known as Glaucomatocyclitic Crisis, is an uncommon inflammatory eye condition that classically affects unilateral at a time. ${ }^{4,5}$ The majority of those who are affected are young to middle-aged adults, whose the eye develops to be increased pressureaccompanied by mild inflammation. Previous studies have not found any racial or ethical predilections for PSS. This disease is considered to be a rare disease. Internationally, the incidence of PSS is 0.4 and 1.9 is the prevalence of PSS. It has the highest rate of occurrence in the age group of 20 years old and 50 years old. The PSS rarely develops in individuals who are aged 60 years old and above as well as the young adults. 4,6-8 It is also possible for a pediatric patient to have PSS. In case of pediatrics, a differential diagnosis of PSS must be included in glaucoma and uveitis. ${ }^{9}$

The history of this rare disease had started in the 40s. Abraham Schlossman and Adolf Posner were the first one who identified PSS in 1948. They gave a brief description of the condition, where Schlossman and Posner mentioned that PSS had the characteristics of both uveitis and glaucoma. The exactunderlying cause of PSS was unknown. ${ }^{5}$ Although some

Correspondence: Kavitha Arunasalam, Faculty of Medicine, Universitas Padjadjaran, Jalan Raya Bandung-Sumedang Km.21, Jatinangor, Sumedang, Indonesia, Phone: +628170206640 Email: kavi.5291@gmail.com 
researches have not been completely proven the cause, they identified a possible herpes virus or human cytomegalovirus association. According to a study conducted in Singapore, out of 24 patients who have cytomegalovirus, $75 \%$ of them have PSS. ${ }^{6,7,10}$

In order to treat the patient, personalization of the management can be conducted in accordance to the state the patient's condition as well possibly recurrence can be avoided. The complications of PSS in this case are said to be long-term increased in intraocular pressure secondary to aqueous outflow impairment, causing damage to the optic nerve head and compromising the visual field. ${ }^{6,7}$ If this disease is handled and managed properly as it should be, then it is said that most of the anterior uveitis attacks will be better in a few days to a few weeks. Nevertheless, it is common that relapses occur.
The objectives of this study are to describe numbers of cases and characteristics of PSS in National Eye Centre Cicendo Eye Hospital.

\section{Methods}

A descriptive study was conducted using 46 medical records. Out of these 46 records, 15 were rejected because 9 were missing and 6 did not have sufficient necessary information. Therefore, the total number of patients taken into account in this study were 31 patients. The study was conducted in the National Eye Centre Cicendo Eye Hospital during the period from August 2009 to July 2011.

The variables studied include age, gender, unilateral or bilateral, frequency of recurrences, and signs and symptoms. Measurement of visual acuity, and intraocular

Table 1 Characteristics of Patients with Posner Schlossman Syndrome

\begin{tabular}{lcc}
\hline \multicolumn{1}{c}{ Characteristics } & N(n=31) & \% \\
\hline Age(years) & 3 & 9.7 \\
$0-20$ & 4 & 12.9 \\
$21-30$ & 12 & 38.7 \\
$31-40$ & 7 & 22.6 \\
$41-50$ & 3 & 9.7 \\
$51-60$ & 2 & 6.4 \\
60 and above & & \\
Gender & 12 & 38.7 \\
Male & 19 & 61.3 \\
Female & & \\
Affected eye & 27 & 87.1 \\
Unilateral & 4 & 12.9 \\
Bilateral & 9 & 29.0 \\
Recurrence & & \\
Signs and symptoms & 31 & 100 \\
Blurred vision & 22 & 71.0 \\
Headache & 8 & 25.8 \\
Headache (according to side of eye affected) & 11 & 35.5 \\
Red eye & 24 & 77.4 \\
Rainbow surrounding light & 13 & 41.9 \\
Pain & 2 & 6.4 \\
Watery eye & 3 & 9.7 \\
Glare & & \\
\hline & & \\
& & \\
& &
\end{tabular}


Table 2 Visual Acuity and Intraocular Pressure after Treatment

\begin{tabular}{lcc}
\hline \multicolumn{1}{c}{ Tests } & N & \% \\
\hline Visual acuity & & \\
Increase & 17 & 54.8 \\
Same with previous & 9 & 29.0 \\
$\quad$ Decrease & 5 & 16.2 \\
Intraocular pressure & & \\
$\quad$ Increase & 20 & 64.6 \\
Same with previous & 2 & 6.4 \\
$\quad$ Decrease & 9 & 29.0 \\
\hline
\end{tabular}

pressure before and after treatment were also carried out. The data were analyzed using frequency distribution.

\section{Results}

Most patients were in the age group of 3140 years old $(38.7 \%)$. Out of 31 patients, majority were female (61.3\%). Most patients suffered from unilateral eye (87.1\%). Only 9 patients $(29.0 \%)$ experienced recurrences. All patients $(100 \%)$ complained of blurred vision, with accompanying vision of rainbow halo surrounding light in 24 (77.4\%), and $22(71 \%)$ had headache (Table 1). After receiving treatment, all 31 patients were measured for visual acuity. The result showed 17 (54.8\%) improved, and measurement of intraocular pressure showed about 20 (64.4\%) improved.

\section{Discussions}

Among 31 patients were diagnosed of PSS, those of middle age patients, who are under the age range of 31-40 years were the highest proportion. This data are in accordance with previous studies. Narang and $\mathrm{Shah}^{4}$ and Harrington $^{8}$ stated that PSS is most commonly found in the age group of 20-50 years. Another study from Taiwan ${ }^{11}$ even mentioned, 36.3 years is the average age of the patients.

Majority patients PSS were female. This is not in accordance to a study conducted by Shenet al. ${ }^{11}$ that stated $58.4 \%$ of patients were male. Also, a study conducted by Japet al. ${ }^{12}$ found that majority of subjects studied 28 were male.

This study, indicates that patients were found with unilateral affected. It is uncommon for bilateral PSS found. Several studies mentioned that characteristics of PSS is unilateral affected. 4,5

The study result showed that only 9 patients who had recurrence of the disease. From signs and symptoms observed, all 31patients came with complaining of blurred vision. This statement is supported by Narang and Shah4 that is also in accordance with Dinakaran and Kayarkar ${ }^{13}$. It was observed that this was the chief complain of all patients.

Twenty four patients (77.4\%) have the symptom of seeing rainbow surrounding the light when they look at any lights (coloured halos), headache $(71.0 \%)$, one side headache of the affected eyes (25.8\%), red eyes (35.5), pain $(41.9 \%)$, watery eyes $(6.4 \%)$ and glare (9.7\%). This is also mentioned by Narang and Shah ${ }^{4}$,Dinakaran and Kayarkar ${ }^{13}$, as well as Omoti and Enock ${ }^{14}$.

To test the outcome of the treatment, the visual acuity and intraocular examination were conducted. The results showed that only 17 patients had better visual acuity and 20 patients had better intraocular pressure. However, this study has limitation due to the using secondary data from medical records, as evidence that from 41 medical record, only 31 were used in this study. There were medical record missing, and incomplete necessary data.

This study concluded that most of PSS cases in National Eye Centre Cicendo Eye Hospital Bandung were female aged 31-40 years, affected on their left eye. All of them were presented with the symptoms of blurred vision, coloured halos, and headache. After treatment, the visual acuity and intraocular pressure were improved. 


\section{References}

1. Segre L. Human eye anatomy: parts of the eye.2010. [Downloaded in May 2012]. Available at: http://www.allaboutvision. com/resources/anatomy.htm.

2. WHO. Fact sheet No 282: visual impairment and blindness. 2011.[Downloaded in May 2012]. Available at:http://www.who.int/ mediacentre/factsheets/fs282/en/.

3. Thylefors B, Negrel AD, Pararajasegaram R, Dadzie KY. Global data on blindness. Bull World Health Organ. 1995;73(1):115-21.

4. Narang SK, Shah SJ. Glaucomatocyclitic crisis syndrome) case report Indian Ophthalmol.1972;20(1):25-7.

5. Shazly TA, Aljajeh M, Latina MA. PosnerSchlossman glaucomatocyclitic crisis. Semin Ophthalmol. 2011;26(4-5):282-4.

6. OakmanJH. Posner-Schlossman syndrome. WebMD LLC. 2012 [downloaded in May 2012]; Available at: http://emedicine. medscape.com/article/1205949overview.

7. Scott KS, Wade NK. PosnerSchlossmansyndrome. The American Uveitis Society.2003; [downloaded on May 2012] Available at: http://www. uveitissociety.org/pages/diseases/pss. html.

8. Harrington JR. Posner-Schlossman syndrome: a case report. J Am Optom Assoc. 1999;70(11):715-23.

9. Burnstein Y, Shelton K, Higginbotham EJ. Glaucomatocyclitic crisis in a child.Am J Ophthalmol.1998;126(1):136-7.

10. CheeSP, Bacsal K, Jap A, Se-ThoeSY, Cheng CL, Tan BH. Clinical features of cytomegalovirus anterior uveitis in immunocompetent patients. Am J Ophthalmol. 2008;145(5):834-40.

11. Shen SC, Ho WJ, Wu SC, Yu KH, Lin HC, Lin YS, et al. Peripheral vascular endothelial dysfunction in glaucomatocyclitic crisis: a preliminary study.Invest Ophthalmol Vis Sci. 2010;51(1):272-6.

12. Jap A, Sivakumar M, Chee SP. Is Posner Schlossman syndrome benign? Ophthalmology. 2001;108(5):913-8.

13. Dinakaran S, Kayarkar V. Trabeculectomy in the management of Posner-Schlossman syndrome. Ophthalmic Surg Lasers. 2002;33(4):321-2.

14. Omoti AE, Enock ME. Glaucomatocyclitic crisis in Edo State, Nigeria: report of two cases. Niger J ClinPract.2008;11(2):162-5. 